SIR-I have read the letters from T.J. Crow (Nature 319, 172; 1986) and D.P. van Kammen (Nature 320, 392; 1986) and greatly appreciate the interest shown by both authors in my letter on the deplorable situation in Japan's psychiatric hospitals (Nature 318, 308; 1986). I should like to repeat once again that the protest action taken against the seventh congress of the Japanese Society for Biological Psychiatry was not directed against either of these visiting scientists.

The reason for the protest was that, in Japan, the scientists responsible for experiments involving humans often refuse to acknowlege criticism. As they remain silent and avoid discussion, concerned people have to resort to protest. Such action is then sensationalized and described as "violent". Protest actions are not illegal and it is regrettable that this is their only response.

This year, on 27 March, we were able to carry out a discussion in the assembly hall of the eighth congress on biological psychiatry held in Kanazawa. We discussed with many members of the society the problem of the previously mentioned experiment on a human fetus carried out by Dr Namba and his colleagues. The doctors actually involved in the experiment did not participate in the discussion. Dr $\mathrm{N}$. Hatotani, the chairman of the board of directors of the society, answered written enquiries supplied beforehand and commented that the experiment of Dr Namba was not to be censured so much. However, the discussion made clear that the investigation carried out by the society into Dr Namba's experiment was inadequate. The society had heard about the experiment from Dr Namba but did not listen to the views of those who had brought up the ethical problems of the experiment. We suggested this was biased and criticized such a method of investigation. Dr Hatotani promised further investigation and discussion.

It seems to us that the measure taken by the society on the ethical problem is quite inadequate. Professor Hidebumi Hazama of Tottori University, a member of the society, has already thrown doubt on the existing ethics of biological psychiatry in Japan and has suggested the need for a system of ethical committees. He had expected the society to take a more positive and serious attitude in this respect (Seishin igaku 27, 118-119; 1985).

We also hear that the president of Gifu University orally admonished Dr Namba and other staff in February 1986 about inadequate procedures in an experiment on a human fetus. In the near future, we expect the ad hoc committee of the Japanese Society of Psychiatry and Neurology to make a report on that experiment.
I have previously stated that some of the published summaries of papers that were to have been delivered at the 1985 Gifu congress provided evidence of unethical conduct. As requested, we will send these summaries to Dr Crow and Dr van Kammen along with several articles on ethical issues in Japan. In my opinion, in order to assess these papers, it is necessary to be conversant with the real background of such research in Japan, for example the very low standing of patients compared with that of doctors, the difficulty of peer review owing to the absolutism of some professors, the closed character of psychiatric departments to avoid discussion and investigation of their research and so on. Such a situation is far from that envisaged in the Proposed international guidelines for biomedial research involving human subjects (CIOMS/WHO, Geneva, 1982)

I sincerely hope that Dr Crow and Dr van Kammen will understand the actual state of Japanese psychiatry. I would advise them both to investigate especially the experiments carried out by $\mathrm{Dr}$ Namba and his colleagues and to refer to the more detailed report of the ad hoc committee of the Japanese Society of Psychiatry and Neurology which we will send them as soon as possible.

Kimio Moriyama

Psychiatrists Union

(Acting chairman)

of Tokyo University,

7-3-1 Hongo, Bunkyo-ku,

Tokyo,

Japan 113

\section{Dutch legislation}

SIR-Your leading articles have frequently highlighted developments in the United States and the United Kingdom concerning ethical and legal aspects of the use of animals in research. New regulations, based on the 1977 Act of Animal Experimentation, recently became effective in the Netherlands.

From 1 January 1986, institutes in which animal experiments are performed require a government licence, issued only if and when a number of conditions are fulfilled. One of these is that the welfare of the experimental animal must be supervised by a specialist in laboratory animal science. This officer, who is on the payroll of the institute, is a veterinarian or biomedical scientist who has taken a oneyear postgraduate course in laboratory animal science and who also has some years' experience in this field. He or she reports to the director of the institute and also to the Inspectorate of Veterinary Public Health. If the animals endure extreme and/or unnecessary discomfort, the inspectorate may advise the Minister of Public Health to withdraw the licence.

A unique provision is that the scientists responsible for animal experiments must have taken an introductory course in laboratory animal science. This applies to all scientists who began animal experimentation after 2 July 1985 . Courses in laboratory animal science are now being incorporated into the biomedical education programme of most universities. The course takes three weeks and its contents have to be approved by the Minister of Public Health. It covers topics such as husbandry, gnotobiology and anaesthesiology as well as the ethical aspects of animal experimentation. The primary goal is to set the stage for a justified and humane use of animals for a scientific purpose

The training programmes are coordinated nationally and commissioned in the department of laboratory animal science at the veterinary faculty in the University of Utrecht.

\section{L.F.M. VAN ZUTPHEN} A.C. BEYNEN

\section{Department of Laboratory}

Animal Science,

Veterinary Faculty,

University of Utrecht,

PO Box 80.166,

3508 TD Utrecht, The Netherlands

H. ROZEMOND

Veterinary Public Health Inspectorate,

Animal Experimentation Section,

Ministry of Welfare, Health and

Cultural Affairs,

PO Box 439 ,

2260 AK Leidschendam, The Netherlands

\section{Search for truth?}

Sir-I disagree with Leo Uzych (Nature $320,480 ; 1986)$ that "science involves a search for truth", and with the inference he draws from this, that the orchestration of data in support of a particular point of view is an impedinient to scientific advancement. I do not see science as being the gradual excavation of a buried city, but rather as the inspirational formation of structures de novo. What one builds is determined by the existing foundations, vision and experimental data. As such, science is not a search for truth but for quality. The extent to which one is justified in advocating individual predilections is therefore a matter for careful judgement based on the consideration that while all constructions are ephemeral, some are more so than others. Unless one is selective with data, all one can hope to produce are bricks for use by others who do not show this restraint.

J. LiEBESCHUETZ

Department of Genetics,

University of Liverpool,

PO Box 147

Liverpool L69 $3 B X, U K$ 